\title{
Performance of a Fibre-Optic Sensor for Monitoring Cracks of Concrete, Masonry and Bituminous Elements
}

\author{
Paulo J. S. Cruz ${ }^{*}$ Abraham Diaz de León ${ }^{1}$ and Christopher K. Y. Leung ${ }^{2}$ \\ ISISE, University of Minho, Azurém, 4800-058 Guimarães, Portugal \\ 'Formerly PhD student at the Civil Engineering Department, University of Minho, \\ Azurém, 4800-058 Guimarães, Portugal \\ ${ }^{2}$ Hong Kong University of Science \& Technology, Clear Water Bay, Hong Kong, P.R.C.
}

(Received November 12, 2007; accepted November 26, 2008)

Key words: fibre-optic sensor, crack sensor, crack monitoring, OTDR

Advances in emerging fibre-optic sensing technology have contributed to the recent development of innovative systems for monitoring the health of civil engineering structures. The main reasons for this development are the reduced weight and dimensions of fibre-optic sensors, their strong immunity to electromagnetic interference, their improved environmental resistance and their scale flexibility for small-gauge and long-gauge measurements. In companion papers, an overview of the challenges related to the design and mechanical characterization of a novel fibre-optic plate sensor for crack monitoring was explained and discussed. The proposed sensor does not require prior knowledge of the locations of cracks, which is a significant advancement over existing crack-monitoring techniques. Moreover, several cracks can be detected, located and monitored using a single fibre. In this paper, we will first present the results of calibration tests on the crack sensor, which aim at determining the relationship between optical intensity loss and crack opening under static conditions. Then, the performance of the sensors with respect to the detection and monitoring of internal and external flexural cracks in concrete, masonry and bituminous elements is assessed. Two versions of the sensor were examined. The first version was externally attached to fibre-reinforced concrete beams and reinforced masonry slabs; the second version was embedded into fibre-reinforced concrete beams and bituminous slabs. The results presented in this paper demonstrate the viability of implementing the attached and the embedded plate sensors to detect the formation and propagation of internal and external cracks and to measure the crack opening width in a wide range of applications.

\section{Introduction}

A crack in a structural element can be subjected to three different loading conditions (modes), as illustrated in Fig. 1. The opening mode involves loading that produces a ${ }^{*}$ Corresponding author: e-mail: pcruz@civil.uminho.pt 
displacement of the crack surfaces perpendicular to the plane of the crack. The shearing mode of loading is due to in-plane shear loads, which cause the two crack surfaces to slide on one another. For this case, the displacement of the crack surfaces is in the crack plane and perpendicular to the leading edge of the crack. The tearing mode of loading is due to out-of-plane shear loading. The displacement of the crack surfaces is in the crack plane but parallel to the leading edge of the crack.

The present paper deals with the monitoring of mode I cracks. Initial work on the monitoring of a mixed mode I - mode II crack can be found in Ref. 1.

In current design procedures such as AASHTO LRFD Standard Specifications for Highway Bridges and ACI 318,,$^{(2,3)}$ the reduction and control of cracking is carried out through the detailing of reinforcements necessary to obtain an acceptable appearance and to achieve the long-term durability of concrete by maintaining a limited distribution of cracks and a reasonable limit to the number or the width of crack openings.

The type and severity of cracks in civil engineering structures are varied. Inactive cracks (such as early shrinkage cracks in concrete structures), once located, usually require corrective action to prevent moisture infiltration. Active cracks can be temporary or continuous. Usually they are related to foundation settling, inherent design flaws, structural overloading and natural environmental factors. Normally they require structural evaluation, active monitoring and corrective action.

Cracks need to be repaired if they reduce the strength, stiffness or durability to an unacceptable level, or if the function of the structure is seriously impaired. In practice, cracks are repaired after the cause is established, and after determining whether the observed cracks are indicative of current or future structural problems, taking into consideration the present and anticipated future loading conditions. This firstly involves a field observation to identify the location and extent of cracking, then a review of the design elements (drawings, specifications, etc.), inspection records and maintenance history. When these do not provide the needed information, a more complex field investigation and structural analysis are recommended.

CEB-FIP and EC2 provide a Europe-wide approach to crack opening evaluation and specify permissible crack opening widths. ${ }^{(4,5)}$ Table 1 presents a general guide for what

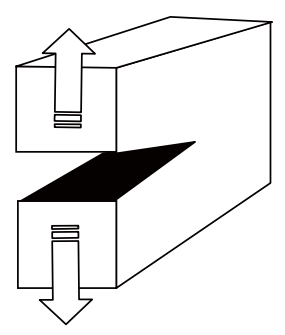

(a)

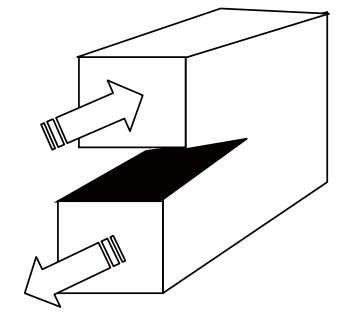

(b)

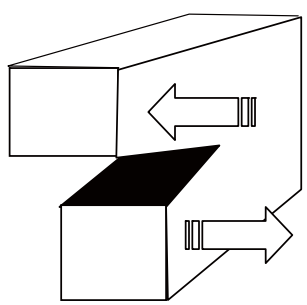

(c)

Fig. 1. Cracking modes and loading conditions in an element: (a) opening mode, (b) shearing mode and (c) tearing mode. 
Table 1

Guide to reasonable crack opening widths for reinforced concrete under service loads.

\begin{tabular}{lc}
\hline Exposure condition & Crack width (mm) \\
\hline Dry air or protective membrane & 0.41 \\
Humidity, moist air, soil & 0.30 \\
De-icing chemicals & 0.18 \\
Seawater and seawater spray, wetting and drying & 0.15 \\
Water-retaining structures & 0.10 \\
\hline
\end{tabular}

could be considered reasonable crack opening widths at the tensile face of reinforced concrete structures under typical conditions. ${ }^{(6)}$ For aesthetic reasons, crack openings ranging from 0.15 to $0.30 \mathrm{~mm}$ may be considered unacceptable. ${ }^{(7)}$

Cracks in pavements are caused by traffic and environmental effects. A typical example of traffic-related cracking is the crack pattern developed under wheel tracks. A typical example of environment-related cracking is transverse cracking over the entire pavement width or part of it, due to contraction induced by a drop in temperature. It is important to recognize the type of cracking as this will affect the placement of sensors for the effective detection and monitoring of the cracks.

Under special conditions such as high friction and a large drop in temperature (or moisture content), longitudinal cracks can also develop, and in such cases typical block cracking patterns are found. Generally speaking, environment-induced cracking is more likely to be associated with the presence of cement-treated layers. However, significant temperature stresses can also develop in asphaltic layers, particularly in cold regions. In these areas, temperatures can become so low that the asphalt mixture becomes stiff, which means that brittle fracture is very likely to occur. It should be noted that temperature cracking can also occur in moderate climates, in spite of the fact that under mild conditions, stresses can relax rapidly in bituminous materials.

If a crack has developed through the entire thickness of the bound layers of a pavement, the maintenance strategy should be selected through the consideration of combined effects (traffic and environmental), although a particular type of cracking is usually initiated. The guidelines for pavement evaluation ${ }^{(8)}$ recommend that the crack opening width and spacing and changes in the crack opening width should be measured while considering possible changes in the climatic conditions (temperature and moisture).

\section{Crack Monitoring}

Because of material inhomogeneities, the exact locations of cracks in a concrete/ masonry structure or bituminous pavement cannot be predicted. Conventional "point sensors" can easily miss the cracks. On the other hand, integrated sensors, which measure the displacement between two points separated by a relatively large distance, are not able to distinguish between the harmless condition of many fine cracks and the undesirable situation of a single wide crack. 
Recently, various researchers have developed crack sensors based on optical fibres. Existing optical crack sensors are, however, limited in their applications. An overview of the characteristics of fibre-optic sensors for crack monitoring and the challenges associated with the development of a "plate sensor," which does not require prior knowledge of the crack locations, allowing the detection, location and monitoring of several cracks using a single fibre, can be found in Refs. 9 and 10.

Brown et al. ${ }^{(11)}$ and Oka et al. ${ }^{(12)}$ have applied Brillouin optical time domain reflectometers (OTDRs) for distributed strain sensing in concrete structures. By measuring the strain-induced frequency change in Brillouin backscattered light as a function of time, the strain distribution along a fibre can be derived. If a fibre is placed inside concrete, high local strain will be induced at a crack. In theory, the crack can hence be detected. In practice, however, the fibre may break owing to the high strain concentration, or debond to allow the averaging of the localized high strain over the debonded length. For cracks with relatively large openings, their presence is indicated by high values of averaged strain measured over a particular region of the specimen. However, since averaging removes the peaks in the strain distribution, the number of cracks within the region and the corresponding crack opening cannot be determined. On the other hand, for cracks with small openings, it is questionable whether the resulting small increase in averaged strain can reveal their presence. Hence, the method may not work for the detection of small cracks with 0.2 to $0.4 \mathrm{~mm}$ openings, which can facilitate water/salt penetration and steel corrosion.

The plate sensor is a polymeric plate with an embedded optical fibre in a zigzag shape that acts as a crack transducer (Fig. 2). The optical fibre is not bonded to the polymeric plate and is free to slide. The principle is that once a crack forms in a structural element, the bonded polymeric plate will crack at the same location and in the same direction as the crack. Before the formation of cracks, the backscattered signal along the fibre should follow a relatively smooth curve (the small loss is due to absorption and scattering). When the zigzag fibre intersects the crack at an angle other than $90^{\circ}$, it must bend to stay

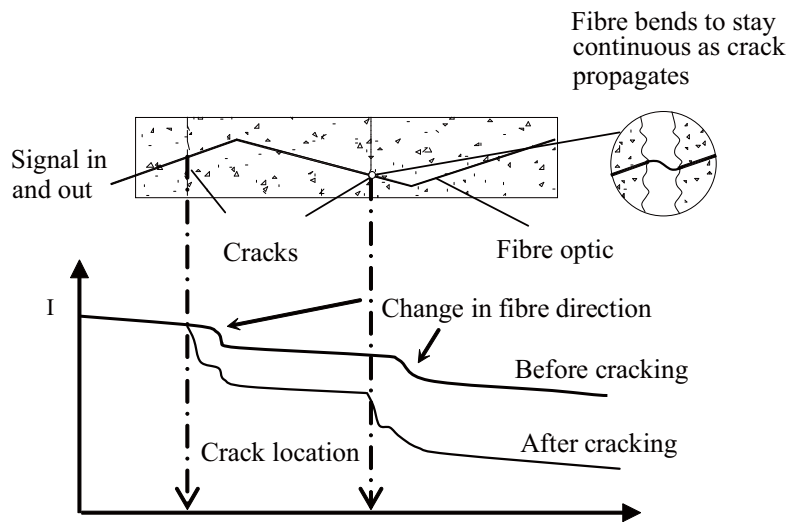

Fig. 2. Principle of operation of the sensor. 
continuous. ${ }^{(9)}$ This perturbation in the fibre is very abrupt, and thus can be considered as microbending. This microbending results in a sharp drop in the optical signal. This power loss can be detected and located using an OTDR, by sending a short pulse into the fibre and monitoring the backscattered signal over time. The location of the crack can be calculated from the time corresponding to the power drop. The crack opening width can also be obtained from the magnitude of the power drop if it has been calibrated.

For the crack sensor to operate properly, strong bonding between the polymeric plate and the structural element must be ensured. If debonding occurs, the plate sensor will not be able to detect the crack opening; likewise, the polymeric material used to build the plate sensor should have sufficient brittleness to break immediately after cracking occurs in the structural element. Otherwise, the sensitivity of the sensor will be significantly affected.

The plates are fabricated using the mould illustrated in Fig. 3. To allow the smooth sliding of the optical fibre inside the plate when the crack is opening, a $256-\mu \mathrm{m}$-diameter steel wire covered with a releasing agent is placed in the mould at the desired position. Then the polymeric material is cast into the mould. Once the material is fully cured, the plate is removed from the mould. The steel wire is subsequently pulled out from the plate and the optical fibre is inserted into the groove left by the wire.

\section{Detection and Measurement of the Power Loss}

When an optical fibre is bent sharply, the lightwave hits the core-cladding interface at an angle smaller than the critical angle, and consequently, total internal reflection can no longer occur. Hence, part of the light leaks into the cladding and is lost.

A power meter can monitor the loss in forward-power intensity. However, if only forward power is measured, the crack location cannot be found. To determine the location, an OTDR can be used to detect the backscattered wave. Glass atoms scatter a small fraction of the light back toward the OTDR by Rayleigh scattering. Irregularities such as splices, connectors and defects in the fibre reflect and scatter additional light. The Rayleigh backscattered signal is also reduced at the bend of the fibre. The OTDR sends an optical pulse forward and monitors the variation of the backscattered signal with time. From the time corresponding to a sudden power loss, one can determine the
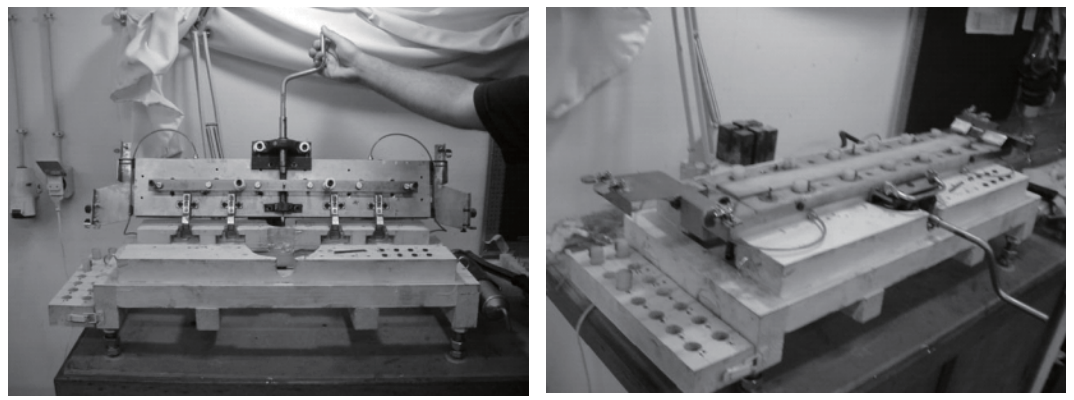

Fig. 3. Mould used to fabricate the plates. 
location of the bend. The intensity loss of the signal can also be found and be used to determine the crack opening width. ${ }^{(9)}$

A typical result using the OTDR is shown in Fig. 4. The plot contains two major components. Rayleigh scattering from the glass produces the background, which gradually declines in intensity with distance from the instrument. The rate of the decline represents the fibre attenuation. The peaks are reflections from discontinuities, analogous to the marks on a radar screen that indicate objects detected by radar.

The distance scale at the abscissa is calculated from the time taken by light to reach a certain point and return. Although the optical pulse is very short and the receiver responds very quickly, the signal received from the part of the fibre closest to the instrument is not useful. This "dead zone" ranges from a few metres to about $20 \mathrm{~m}$. The largest peak in Fig. 4 is the reflection at the end of the fibre. The next largest peak is the reflection from a connector. It is possible to see that the signal after the connector is slightly lower than it was before the connector; this drop is due to absorption and scattering at the connector. Mechanical splices also reflect some light back to the instrument and cause a measurable loss, but both loss and reflection are smaller in this case. The plot also shows the effect of a fusion splice, which causes a small loss but does not reflect light back to the OTDR. For a good fusion splice, the loss can be nearly undetectable.

The OTDR's major attraction is its convenience of use and ability to detect cable faults or bends remotely at a distance of up to tens of kilometres by sending a test signal from one end of a cable segment. This allows a technician to locate a broken or severely deformed fibre segment in a long cable without inspecting the whole cable. It is important to realize that OTDR loss measurements are not as accurate as the direct measurement of attenuation. The fraction of light scattered back toward the instrument varies with the type of fibre. Some splices between different fibres appear to be "gainers;" the excess backscattering in a more distant part of the cable makes it appear as if the signal power has increased.

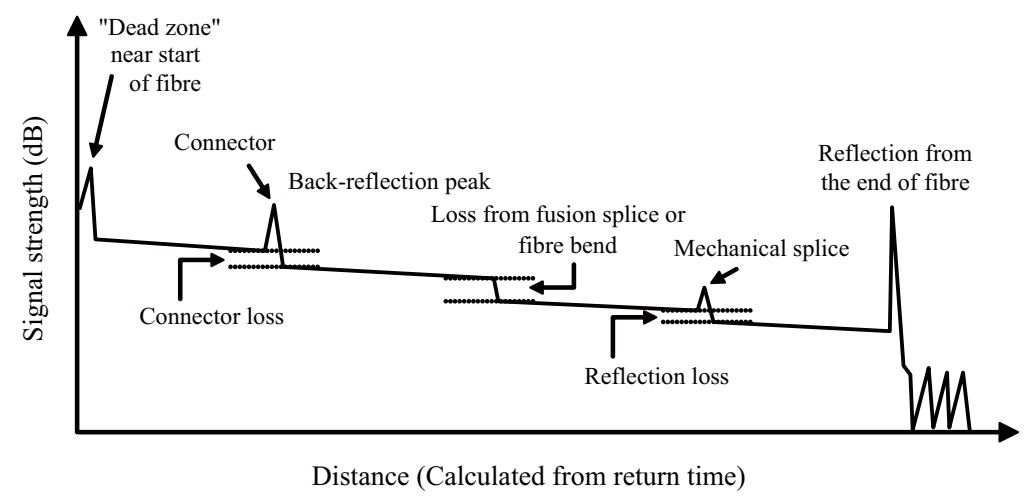

Fig. 4. Features of an OTDR plot (not to scale). 


\section{Wiring Configuration}

Figure 5 shows the wiring configuration proposed for use with a miniature OTDR. This configuration includes two fibre cylinders to separate the reflection at the connection with the OTDR and that at the end of the optical fibre. Four kilometres of fibre is the minimum standard length provided by commercial suppliers. The length of optical fibre used for fabricating the plate sensor (which includes the zigzag fibre inside the plate as well as the length of fibre protruding from the ends of the plate) was determined to be 3 $\mathrm{m}$ after several tests and manual calibrations.

\section{Calibration Tests}

As discussed above, the principle of operation of the sensor is based on the intensity variation of the optical power within the optical fibre due to the initiation and opening of cracks. If the optical power is calibrated, the crack opening width can be obtained from the magnitude of the power loss.

Several calibrations were performed in this study to determine and predict the behaviour of the sensor under different operating conditions. Figure 6 shows the specimens used in the calibration tests. The specimen dimensions are representative of the parameters determining the sensor, i.e., the length of the fibre in the calibration specimen is similar to the length between the inflection points of the zigzag fibre inside the sensor plate. Before the polymer is cast to fabricate the specimen, an inclined steel

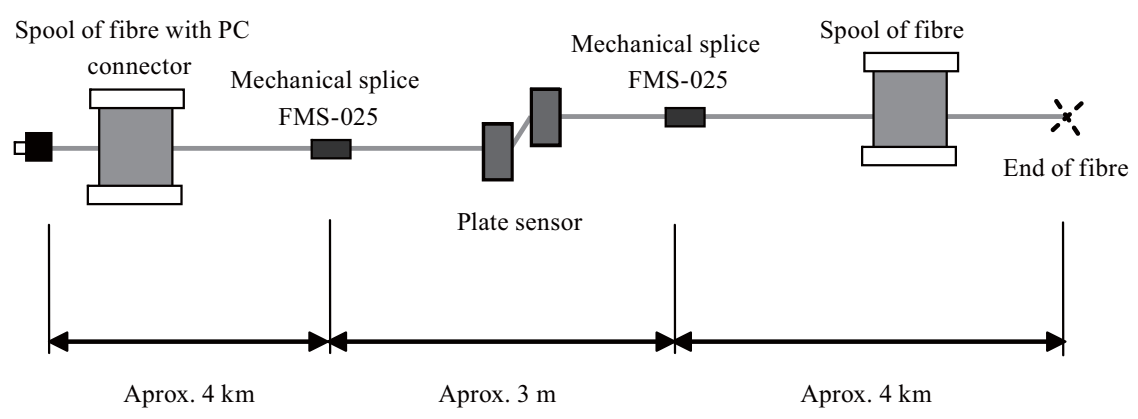

Fig. 5. Proposed wiring configuration.

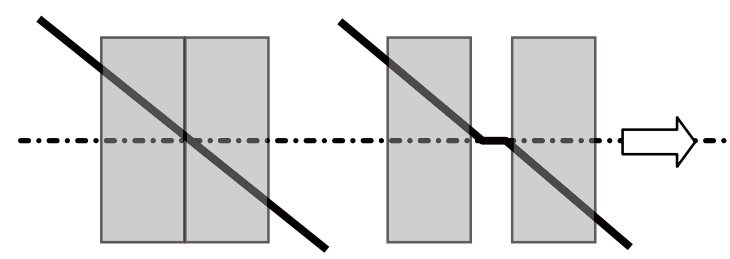

Fig. 6. Specimen used in the calibration tests. 
wire is placed inside the mould. After the polymer hardens, the steel wire is extracted and the specimen is cut into two halves using a diamond saw to simulate the existence of a linear crack. Then, the optical fibre is manually inserted in the hole formed by the extraction of the steel wire.

As mentioned in $\S 3$, there are two main devices used to measure the backscattered intensity: (1) the power meter and (2) the OTDR. In this study both devices were used and the results are discussed in detail.

\subsection{Using a mechanical crack simulator and a power meter}

The calibration tests were carried out using the mechanical crack simulator described by Leung et al. ${ }^{(9)}$ This simulator, illustrated in Figs. 7 and 8, was designed so that the crack opening width could be measured using a linear variable differential transformer (LVDT). The testing device comprises a fixed block and a movable block. The moving part rests on two hardened steel rods and has four precision ball bearings to keep it aligned and moving with very little friction. The specimen is clamped onto the blocks using tightened screws (Fig. 7). Using a motor and a connecting rod, the movable block is pulled away from the fixed block to simulate crack opening. ${ }^{(13)}$

The procedure to calibrate the corresponding intensity loss versus the crack opening width began with the installation of the optical fibre in the hole of each specimen. Then each half of the specimen was sequentially clamped. The recording of the displacement and optical power loss started when the motor was turned on to displace the movable

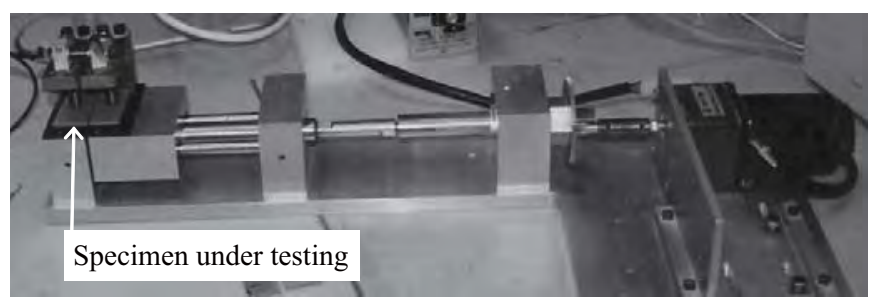

Fig. 7. Photograph of the mechanical crack simulator described by Leung et al. ${ }^{(9)}$

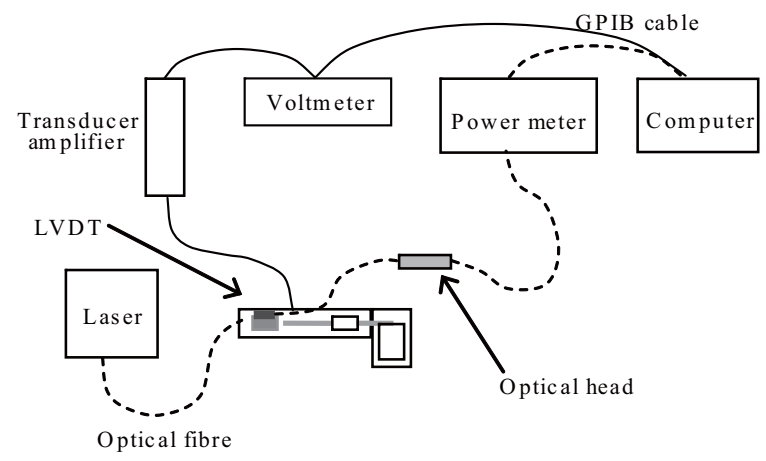

Fig. 8. Experimental setup for calibration tests. 
block and stopped when the displacement reached $2 \mathrm{~mm}$. After the completion of the test, the movable block was pushed back to its original position so that the optical fibre returned to the straight configuration. Using the same specimen, the test was repeated five times. As part of the fibre coating might be scratched when the fibre is bent and pulled in the test, a different part of the fibre should be used in each test. Therefore, before each test, the fibre was pulled by a few centimetres to move a new part of fibre to the location of the 'crack.'

Figures 9 and 10 show the relationship between optical power loss (in $\mathrm{dB}$ ) and crack opening width (in $\mathrm{mm}$ ) obtained in the calibration tests carried out using two different versions of the plate sensor with the fibre at 15 and $30^{\circ}$ to the crack normal, respectively.

\subsection{Using a manual crack simulator and an OTDR}

The calibration process using an OTDR is much more time- and resource-consuming than that using a power meter. However, the calibration curves obtained from this process can help us estimate the behaviour of the sensor in real applications in which data acquisition is performed using the miniature OTDR with the wiring configuration shown in Fig. 5.

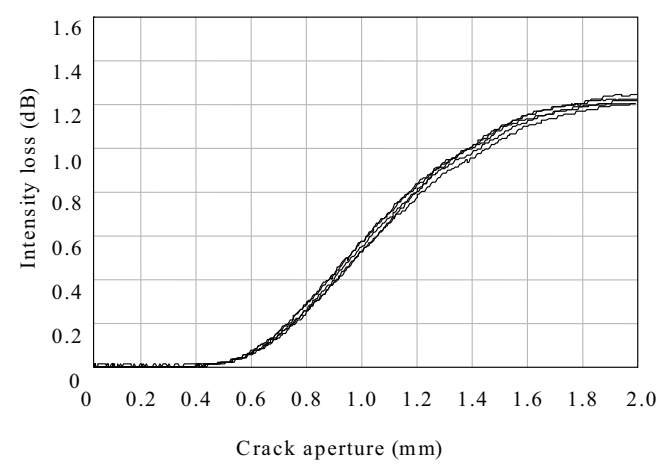

Fig. 9. Calibration of a $15^{\circ}$ sensor made with Pol. 2 al polyester.

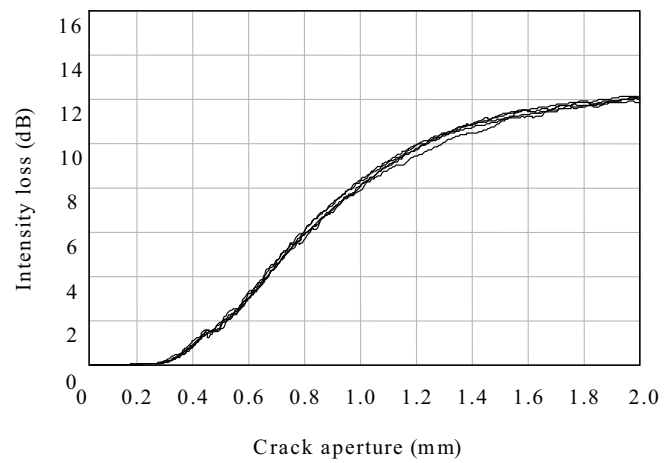

Fig. 10. Calibration of a $30^{\circ}$ sensor made with Pol. $2 \mathrm{a} 1$ polyester. 
Figure 11 shows the manual crack simulator used to simulate the crack opening and to perform the calibrations using the miniature OTDR. The device is made of a bench micrometer assembled with two blocks of aluminium resting on two movable parts coupled to a hardened steel base. The base is designed to keep the movable parts and the ball bearings inside them aligned without rotation, and moving with very little friction.

After the two sides of the specimen were clamped to the aluminium blocks, the movable part below one of the blocks was fixed by tightening a screw at its bottom. By turning the spindle of the micrometer, the other block was moved to separate the fixed and movable blocks to simulate crack opening. Measurements were performed at 0.1 $\mathrm{mm}$ intervals since the accuracy of the micrometer was $0.005 \mathrm{~mm}$.

Because of the low spatial resolution of the miniature OTDR, each point in the output of the OTDR represents the integrated loss over several metres or several tens of meters of fibre depending on the optical pulse width. After some preliminary tests, it was found that an optical pulse width of $100 \mathrm{~ns}$ and a fibre length of $3 \mathrm{~m}$ between the mechanical splices (that connect the sensor to the two fibre cylinders shown in Fig. 5) provided the most consistent results. Figure 12 shows the relationship between optical

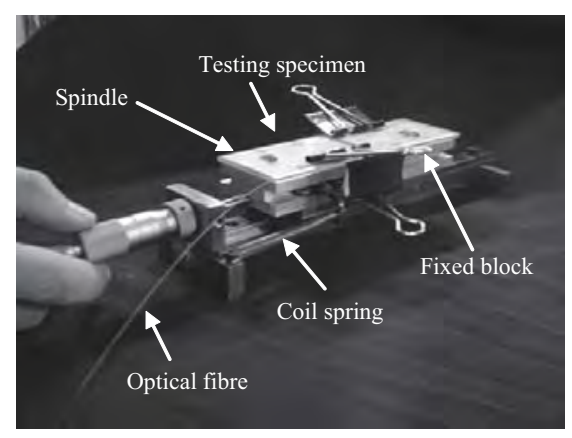

Fig. 11. Photograph of the manual crack simulator.

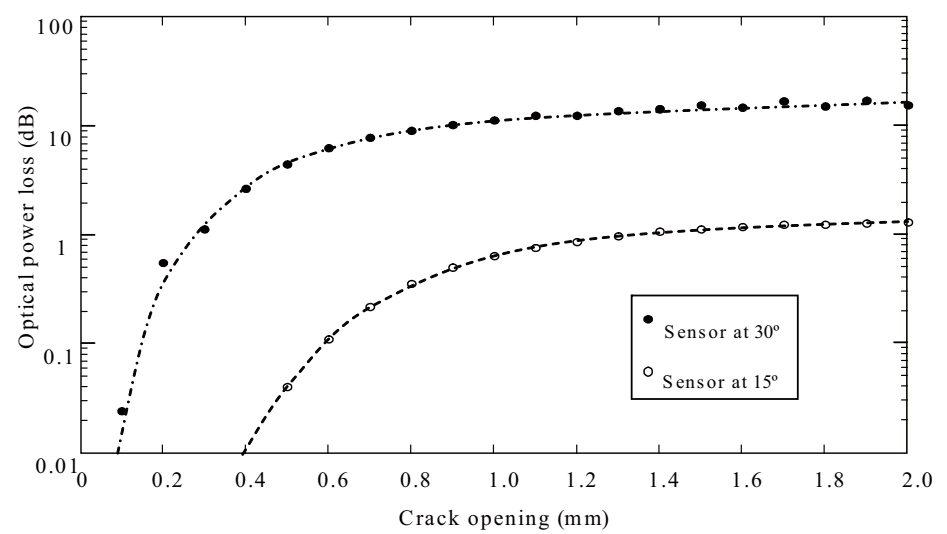

Fig. 12. Calibration of 15 and $30^{\circ}$ sensors made with Pol. 2a1 polyester with the addition of A1200 abrasive. 
power loss (in $\mathrm{dB}$ ) and crack opening width (in $\mathrm{mm}$ ) obtained in the calibration tests carried out with two different versions of the plate sensor, with the fibre at 15 and $30^{\circ}$ to the crack normal, respectively. The results from the OTDR measurements are shown as dots since they are taken at discrete crack opening widths. The averaged results from the direct power measurement are shown as the dotted curve. For the $15^{\circ}$ sensor, very good agreement can be observed between the direct power and OTDR measurements. For the $30^{\circ}$ sensor, the OTDR measurements tend to show a higher loss for the same crack opening, but the trends of the two measurements are very similar. Generally speaking, the agreement can be considered to be satisfactory.

\subsection{Discussion of the calibration results}

There are many different design parameters that affect the performance characteristics of the sensors. In addition to the optical and mechanical properties of the fibre, the characteristics of the polymeric coating and the interfacial conditions between the matrix of the polymeric plate and the fibre, there are other factors that have a direct effect on the behaviour of the sensors:

- The existence of imperfections in the matrix around the fibre that may cause unequal optical power loss for the same crack opening width,

- Irregularities in the displacement imposed by the crack simulators,

- The diameter of the hole in which the fibre is placed,

- Occasional deviations in the alignment of the plates when clamping the specimens.

Despite all these sources of uncertainty, the comparison of the performance characteristics obtained from the calibration tests performed in this study indicates that the results achieved by both direct and backscattered power measurements exhibit reasonable agreement. This therefore indicates that useful results can be obtained under practical conditions.

\section{Laboratory Tests}

Experimental tests on fibre-reinforced concrete beams and masonry slabs were performed using the plate sensor to measure the external opening width of a single crack.

In the experiments, the wiring configuration and setup of the OTDR corresponded to those shown in Fig. 5. An optical fibre of $3 \mathrm{~m}$ length was inserted into the hole of the plate sensors by hand, so that the ends of the optical fibre were equidistant from the centre of the plate.

The material used to fabricate the sensor was Pol. 2al polyester with the addition of A1200 abrasive at $20 \%$ volume $^{(10)}$ to ensure sufficient brittleness for the plate to crack simultaneously with the structural element.

In all the tests, the crack opening width obtained using the plate sensor was compared with the displacement obtained using an LVDT. 


\subsection{Applications of the surface-attached plate sensor}

\subsubsection{Steel-fibre-reinforced concrete beams}

The first evaluation of the surface-attached plate sensor involved the flexural testing of two steel-fibre-reinforced concrete (SFRC) beams with a cross section of $10 \times 10 \mathrm{~cm}^{2}$ and a span of $80 \mathrm{~cm}$. The bearing supports were separated by $75 \mathrm{~cm}$, while the two points of loading application were separated by $10 \mathrm{~cm}$. A plate sensor was attached to the bottom of the beam. In the centre of each beam, notches of $5 \mathrm{~mm}$ (width) $\times 20 \mathrm{~mm}$ (depth) were cut at both lateral faces. The purpose of notching the beams was to define the initial location of cracking, so that crack opening could be simultaneously monitored using an LVDT attached to the sensor plate at the location of the potential crack (Fig. 13).

Using SFRC instead of reinforced concrete, the crack should propagate in a more stable manner, without sudden 'jumps' in the crack opening width. The measurement of the crack opening width can then be more easily performed. The SFRC used was produced using hooked-end DRAMIX ${ }^{\circledR}$ ZP305 steel fibres with a length of $30 \mathrm{~mm}$, a diameter of $0.55 \mathrm{~mm}$, an aspect ratio of 55 and a yield strength of about $1100 \mathrm{~N} / \mathrm{mm}^{2}$ (DRAMIX, 1998). ${ }^{(14)}$ The constituents of the concrete mix and their proportions are summarized in Table 2.

The specimen loading was accomplished with a controlled velocity of $0.005 \mathrm{~mm} / \mathrm{s}$. Beams were subjected to 9 levels of sustained loading, each with a vertical displacement increment of $0.4 \mathrm{~mm}$. At each level, the loading was maintained for $30 \mathrm{~s}$ to perform the data acquisition using the OTDR. To detect and compare the crack measurements under similar conditions, one beam was tested using the $15^{\circ}$ sensor and the other one using the $30^{\circ}$ sensor.

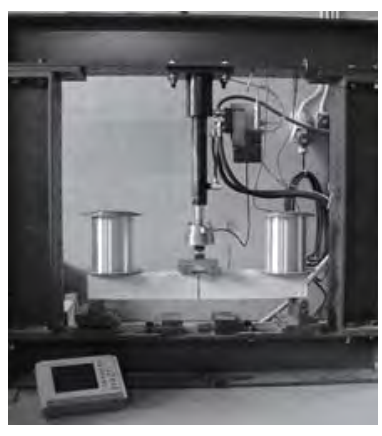

(a)

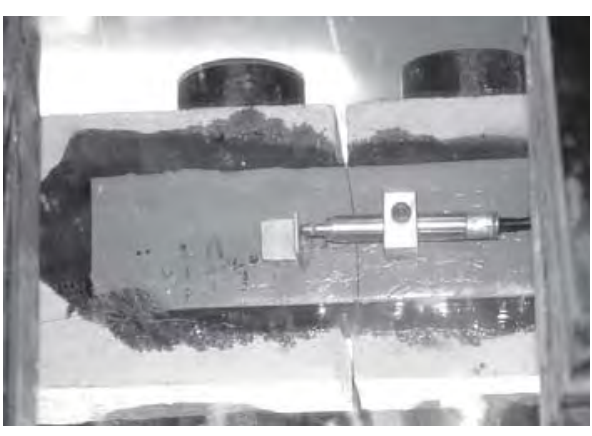

(b)

Fig. 13. Plate sensor externally attached to an SFRC beam: (a) front view and (b) plate sensor.

Table 2

Composition of the SFRC.

\begin{tabular}{cccccccc}
\hline $\begin{array}{c}\text { Cement I } \\
42.5 \mathrm{R} \\
\left(\mathrm{kg} / \mathrm{m}^{3}\right)\end{array}$ & $\begin{array}{c}\text { Fly ash } \\
\left(\mathrm{kg} / \mathrm{m}^{3}\right)\end{array}$ & $\begin{array}{c}\text { Fine river } \\
\text { sand } \\
\left(\mathrm{kg} / \mathrm{m}^{3}\right)\end{array}$ & $\begin{array}{c}\text { River } \\
\text { sand } \\
\left(\mathrm{kg} / \mathrm{m}^{3}\right)\end{array}$ & $\begin{array}{c}\text { Coarse } \\
\text { aggregate } \\
4 / 11\left(\mathrm{~kg} / \mathrm{m}^{3}\right)\end{array}$ & $\begin{array}{c}\text { Coarse } \\
\text { aggregate } \\
11 / 16\left(\mathrm{~kg} / \mathrm{m}^{3}\right)\end{array}$ & $\begin{array}{c}\text { Steel } \\
\text { fibres } \\
\left(\mathrm{kg} / \mathrm{m}^{3}\right)\end{array}$ & $\begin{array}{c}\mathrm{A} /(\mathrm{C}+\mathrm{FA}) \\
\text { ratio }\end{array}$ \\
\hline 200 & 20 & 475 & 486 & 453 & 532 & 30 & 0.65 \\
\hline
\end{tabular}


Figure 14 shows the relationship between optical power loss and crack opening width. The calibration curves presented in $\$ 5.2$ are also shown. The concordance between the results obtained in the laboratory and in the calibration tests is extremely high if we consider the following aspects:

- In the calibration tests two separate blocks were employed so that the simulated crack was perfectly straight. On the other hand, the crack formed in the plate sensor on the SFRC beam is clearly not straight (Fig. 13(b)). This will have an effect on the bending of the fibre. According to the results of numerical simulations, the effect is more significant for the small-angle sensor.

- The inclination of the crack may also indicate that the beam is not undergoing simple bending - there may be some torsion introduced by the loading rods and supporting rods as the beam is not a perfect prism. While the torsion is not expected to be very high, it can introduce some shear displacement along the crack in addition to its opening. The inclination of the crack may also be due to a slight misalignment of the specimen. Then, the crack opening direction is not at 15 or $30^{\circ}$ to the optical fibre.

- Regarding the sensor plate, small pores may exist in the polymer because no vacuum was applied during the fabrication process. At the location where the crack intersects the fibre, if the porosity is relatively high, local matrix cracking may occur to 'relax' the fibre, thus reducing the bending curvature as well as the optical power loss. This effect is again more significant when the fibre angle is small.

- After cracking occurs in the structural element, there is an inevitable delay in the response of the plate sensor. This is because the polymeric material used to fabricate the sensor is more ductile than the concrete used for making the beams, even when brittle particles are incorporated in the polymer. This explains why the displacement measured using the LVDT is greater than the value predicted using the sensor (Fig. 14).

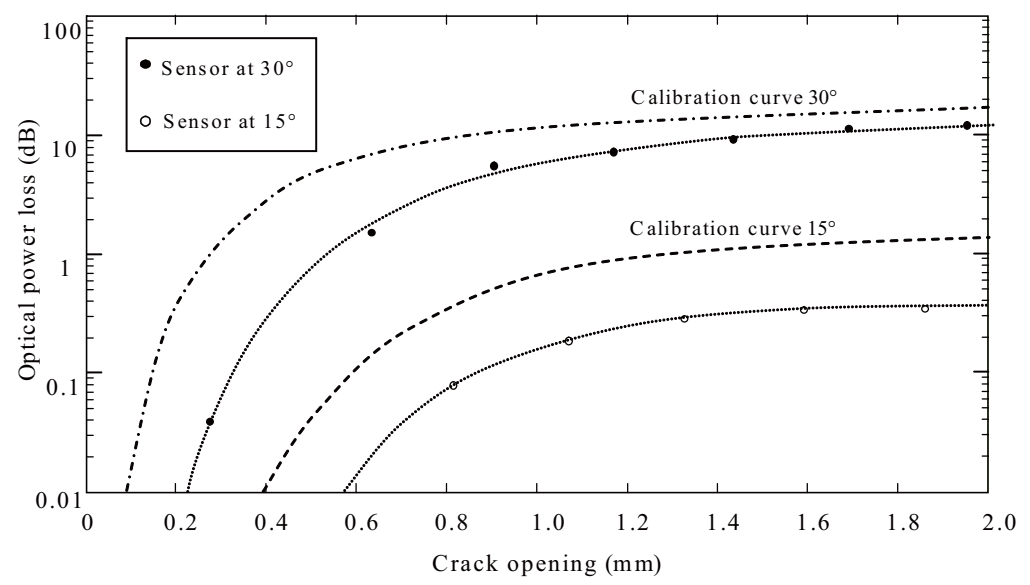

Fig. 14. Experimental results for SFRC beams. 
- The LVDT is placed several $\mathrm{mm}$ from the bottom of the beam, whereas the plate sensor was directly glued to the beam. As the rotation of the section containing the crack occurs, the LVDT, which is further away from the beam surface, will measure a larger displacement.

\subsubsection{Masonry slabs}

After the tests using the SFRC beams, the applicability of the sensor to masonry structures was studied. This type of structure introduces some additional difficulties related to the irregularity of the masonry surface and the strong inhomogeneity of the material.

In this study, a prefabricated reinforced masonry slab was used. Details of the procedure for building the slab and the mechanical properties of the materials can be found in Ref. 15. The cross-section dimensions are $9.5 \times 45.5 \mathrm{~cm}^{2}$ and the span is 87.5 $\mathrm{cm}$. Figure 15 shows the configuration of the slab with the specimen dimensions, loading position and plate sensor location.

The slab was tested under a three-point-bending condition (Fig. 16(a)). A notch was cut in the bottom face at the centre of the span to define the initial location of cracking. The specimen was loaded under a controlled velocity of $0.005 \mathrm{~mm} / \mathrm{s}$. The slab was subjected to 9 levels of sustained loading, each with a $0.4 \mathrm{~mm}$ increment in

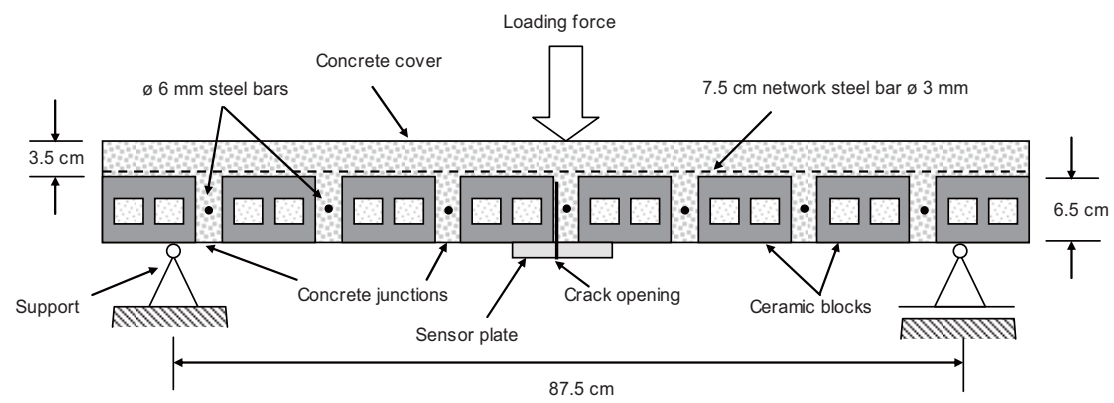

Fig. 15. Configuration of the reinforced masonry slab.

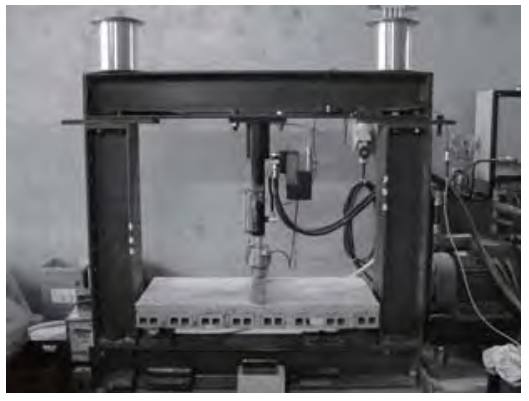

(a)

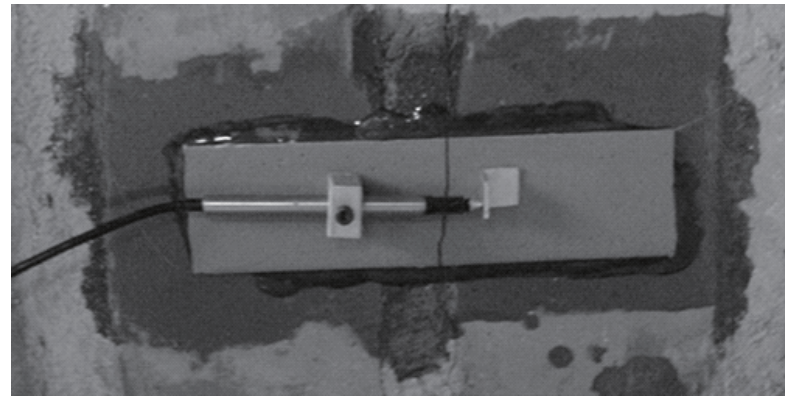

(b)

Fig. 16. Plate sensor externally attached to a masonry slab: (a) front view and (b) plate sensor. 
vertical displacement. At each level, the loading was maintained for $30 \mathrm{~s}$ to perform the data acquisition using the OTDR. To compare the crack measurements with the measurements obtained in the concrete beams, the masonry slab was tested using the sensor with the optical fibre at an angle of $15^{\circ}$.

Figure 17 shows the relationship between optical power loss and crack opening for different tests. The calibration curves obtained in $\$ 5.2$ are also shown. The concordance between the results obtained in this application and in the calibration test is excellent. In this case the optical intensity loss is higher than the calibration results for the $15^{\circ}$ sensor. As can be observed in Fig. 16(b), the angle between the crack normal and the fibre is close to $20^{\circ}$, indicating possible load misalignment resulting in an increased loss.

\subsection{Applications of the embedded plate sensor}

Figure 18 shows the preparation of a $15^{\circ}$ plate sensor to be embedded in concrete or bituminous elements. To protect the part of the fibre outside the sensor plate from breakage, two thin plastic pipes of $1 \mathrm{~m}$ length were used on each side. Grease was

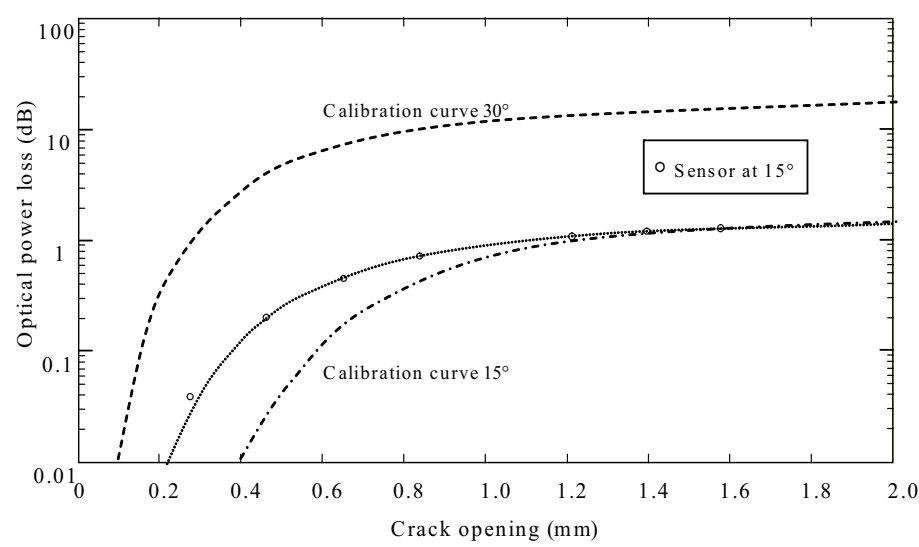

Fig. 17. Experimental results for the masonry slab.

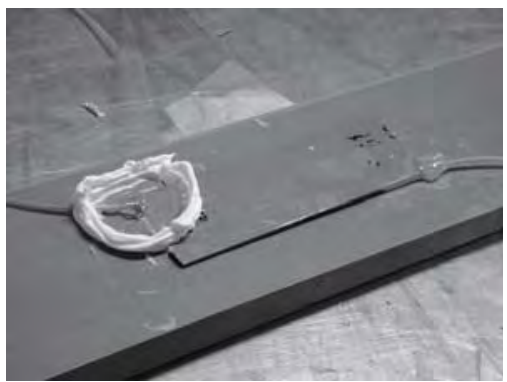

(a)

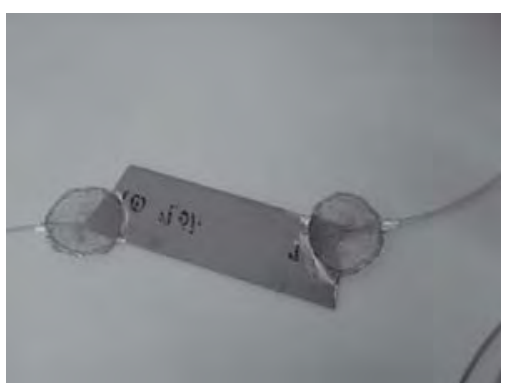

(b)

Fig. 18. Preparation of an embeddable plate sensor: (a) sealing of joint to protect the optical fibre and (b) plate sensor to be embedded. 
applied to allow free sliding of the optical fibre inside the pipes, so that when the crack opens, the fibre can move into the space between the opposing crack surfaces without resistance. The location of the joint between the plastic pipes and the sensor was sealed using a small quantity of pure polyester. Finally, to prevent damage during transportation and installation, the exposed ends of the optical fibre were protected using plastic bags.

To detect and measure the crack opening inside a member, an SFRC beam with a cross section of $15 \times 15 \mathrm{~cm}^{2}$ and a length of $60 \mathrm{~cm}$ was prepared. The constituents of the concrete mix and their proportions are presented in Table 3.

The beam was tested under a three-point-bending condition using a manual hydraulic pump to control the crack opening of the beam. The bearing supports were separated by $50 \mathrm{~cm}$. At the centre span of the beam a $5 \times 20 \mathrm{~mm}^{2}$ notch was cut at the bottom to define the initial location of cracking.

Figure 19 shows the installation of the embedded plate sensor and the experimental test performed to detect and measure the crack opening. The plate sensor was fixed to a couple of steel rebars (Fig. 19(a)) and placed inside the mould at a distance of $3 \mathrm{~cm}$ from the bottom of the mould (Fig. 19(b)). The steel rebars made it possible for the plate sensor to remain perfectly vertical during and after the vibration of the concrete. The LVDT attachment was designed to monitor the opening of the crack at the level of the optical-fibre sensor. The loading increment was controlled so that the crack opened in steps of $0.2 \mathrm{~mm}$ (as measured using an LVDT at the level of the sensor plate). After each step the loading was maintained for $30 \mathrm{~s}$ to perform the data acquisition using the OTDR.

In the rehabilitation of an old and cracked pavement by the incorporation of a new layer of compacted asphalt mixture, the propagation of old cracks into the new layer

Table 3

Composition of the SFRC.

\begin{tabular}{cccccccc}
\hline $\begin{array}{c}\text { Cement I } \\
\begin{array}{c}42.5 \mathrm{R} \\
\left(\mathrm{kg} / \mathrm{m}^{3}\right)\end{array}\end{array}$ & $\begin{array}{c}\text { Fly ash } \\
\left(\mathrm{kg} / \mathrm{m}^{3}\right)\end{array}$ & $\begin{array}{c}\text { Fine river } \\
\text { sand } \\
\left(\mathrm{kg} / \mathrm{m}^{3}\right)\end{array}$ & $\begin{array}{c}\text { River } \\
\text { sand } \\
\left(\mathrm{kg} / \mathrm{m}^{3}\right)\end{array}$ & $\begin{array}{c}\text { Coarse } \\
\text { aggregate } \\
4 / 11\left(\mathrm{~kg} / \mathrm{m}^{3}\right)\end{array}$ & $\begin{array}{c}\text { Coarse } \\
\text { aggregate } \\
11 / 16\left(\mathrm{~kg} / \mathrm{m}^{3}\right)\end{array}$ & $\begin{array}{c}\text { Steel } \\
\text { fibres } \\
\left(\mathrm{kg} / \mathrm{m}^{3}\right)\end{array}$ & $\begin{array}{c}\mathrm{A} /(\mathrm{C}+\mathrm{FA}) \\
\text { ratio }\end{array}$ \\
\hline 300 & 30 & 288 & 598 & 410 & 541 & 30 & 0.45 \\
\hline
\end{tabular}

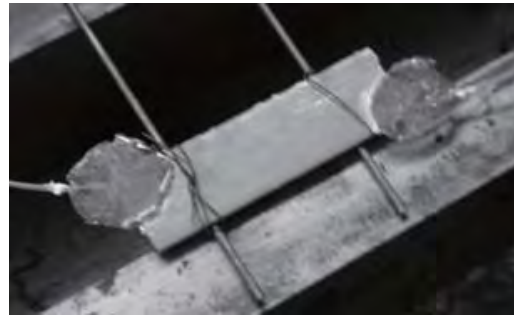

(a)

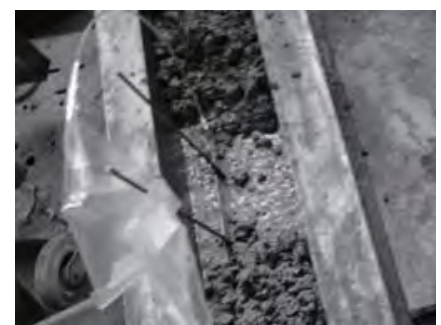

(b)

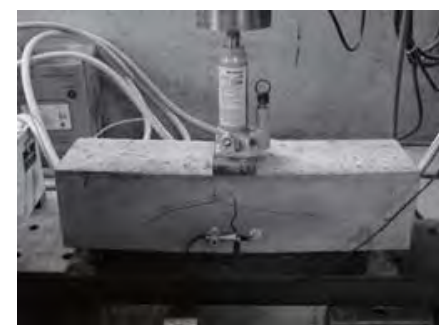

(c)

Fig. 19. Plate sensor embedded in an SFRC beam: (a) fixing of the plate sensor, (b) installation of the plate sensor and (c) crack opening at the level of the plate sensor. 
often occurs. To simulate such a situation, an asphalt slab with two layers was produced, and plate sensors were placed between the layers. The propagation of cracks from one layer to the other could then be monitored.

The asphalt mixture was produced using a mechanical mixer in a hot vessel that maintained the aggregate at $175^{\circ} \mathrm{C}$ before adding the asphalt binder at $160^{\circ} \mathrm{C}$. The mixture was removed from the vessel after the aggregate was thoroughly mixed together with the asphalt binder. The mixture was compacted at $155^{\circ} \mathrm{C}$ using a vibrating wheel roller passed over a metallic mould to obtain an asphalt slab of 10 (two layers of $5 \mathrm{~cm}$ ) $\times$ $50 \times 75 \mathrm{~cm}^{3}$.

The asphalt mixture used in this experiment was a conventional dense-grade bituminous mixture with a maximum aggregate size of $12 \mathrm{~mm}^{(16)}$ and a 5.5\% 50/70 pen asphalt binder with a Marshall mixture design. The composition of the aggregate in the mixture includes four grades: 1) crushed granite stone, particle size 6-12 mm (59\%); 2) crushed granite stone, particle size 4-10 mm (23\%); 3) fine crushed granite stone, particle size $\leq 4 \mathrm{~mm}(15 \%)$; and 4) calcareous filler $(3 \%)$. For details of the mechanical properties of the materials, and the testing, analysis and numerical modelling of the employed asphalt mixture, Ref. 17 can be consulted.

To simulate the characteristics of an old pavement, the mechanical properties of the asphalt mixture comprising the bottom layer were artificially degraded to reduce the binder resilience by keeping the mixture inside an oven at $135^{\circ} \mathrm{C}$ for $24 \mathrm{~h} .{ }^{(18)}$ Figure 20 shows the procedure for the production of the asphalt slab with the plate sensor installed between the two layers.

The asphalt slab obtained by this procedure was cut into two specimens with dimensions $10 \times 35 \times 50 \mathrm{~cm}^{3}$. These specimens were tested under a three-point-bending condition (Fig. 21(a)). The bearing supports were separated by $40 \mathrm{~cm}$.

In the centre of the bottom face, a $5 \times 20 \mathrm{~mm}^{2}$ notch was introduced (Fig. 21(b)) to define the initial location of cracking. The LVDT attachment was designed to monitor the opening of the crack at the level of the optical-fibre sensor. The loading increment

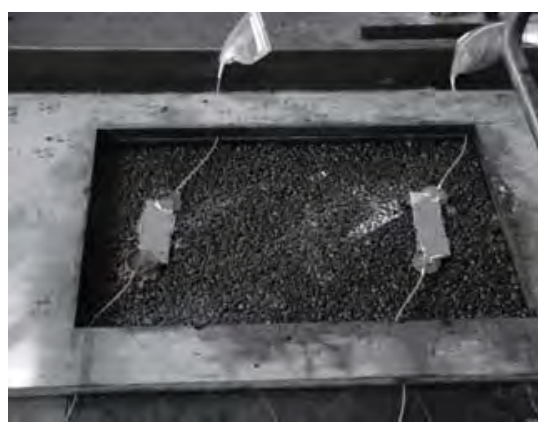

(a)

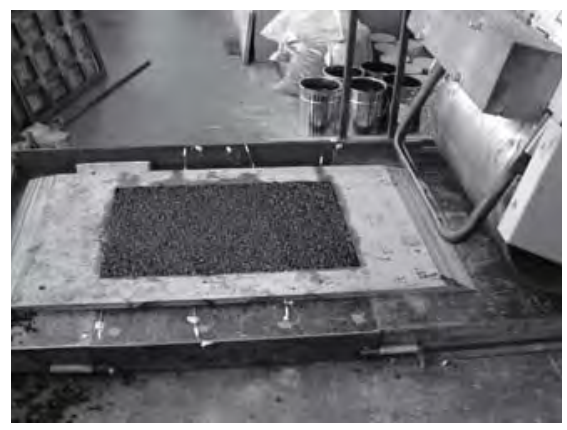

(b)

Fig. 20. Fabrication of the asphalt slab with the plate sensor installed between the two layers: (a) installation of plate sensors on the bottom layer and (b) compaction of top layer using vibrating wheel roller. 


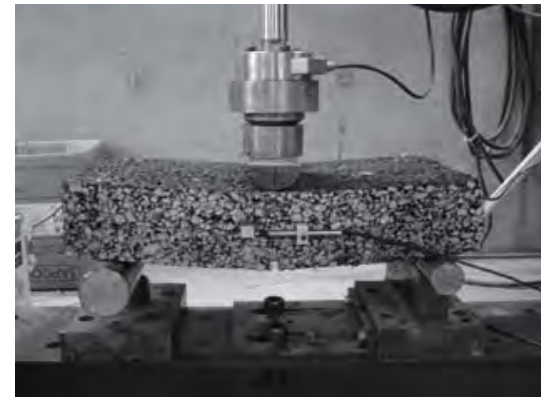

(a)

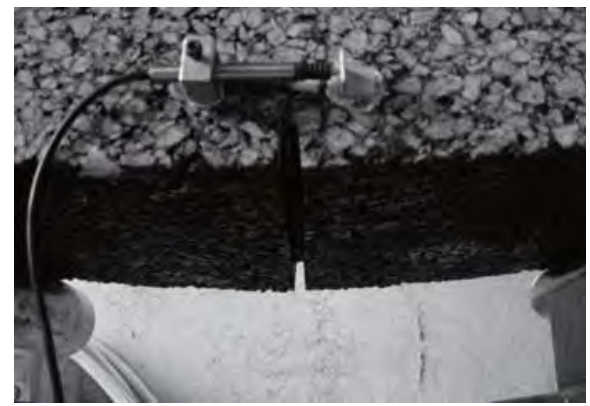

(b)

Fig. 21. Loading test on the bituminous slab: (a) general view and (b) $5 \times 20 \mathrm{~mm}^{2}$ notch cut at the bottom.

was controlled so that the crack opened in steps of $0.2 \mathrm{~mm}$. After each step the loading was held for $30 \mathrm{~s}$ to perform the data acquisition using the OTDR.

Figure 22 shows the relationship between optical power loss and crack opening width for different tests, together with the calibration curves presented in $\$ 5.2$.

The agreement between the results obtained in these tests and in the calibration test is satisfactory, particularly for higher values of crack opening width.

\subsection{Additional Remarks}

In this investigation, three members with externally attached plate sensors and two members with internally embedded plates were tested. Despite the various sources of errors discussed in $\$ 6.1 .1$, the measured loss vs crack opening width results for the sensor plates are in good agreement with the calibration characteristics obtained in the laboratory for four of the five tested members. The viability of the sensor plate for practical applications has therefore been demonstrated.

For the internally embedded sensor, the use of thin tubes to encase the part of the fibre outside the plate is effective in protecting the fibre from damage and allowing it to slide into the space between the crack surfaces once the crack is formed. The capability of the fibre to move inside the plates is a key factor in ensuring the extended service life of the sensors under practical conditions, because the opening and closing of cracks will not expose the optical fibre to large and abrupt forces.

When the sensor is employed for concrete structures, its durability can be a concern after the first crack is formed. Before cracking, the optical fibre is well protected inside the polymeric sheet. However, after the first crack is formed, it is possible for the alkaline ions in concrete to attack the fibre. This problem is more severe for an embedded sensor and becomes a concern for multiple crack detection and monitoring if various cracks are formed at very different times. In future work, sensors with small crack openings $(0.1$ to $0.3 \mathrm{~mm}$ ) should be tested in a concrete environment to quantify their durability after cracking. In practice, the following strategy can be adopted. After 


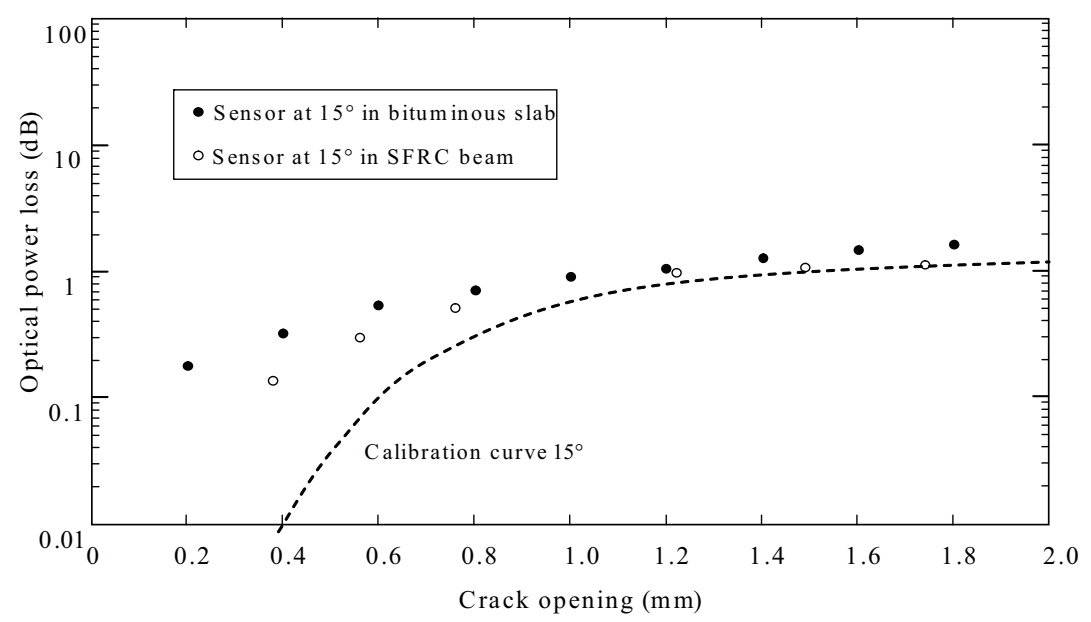

Fig. 22. Experimental results for SFRC beams and bituminous slabs.

the crack opening reaches a width that is harmful to the optical fibre, the crack should be sealed with epoxy resin. By protecting the fibre from attack and breakage, the formation of new cracks in other locations along the fibre can still be detected and monitored.

The robustness of the sensor is highlighted in the experiment using bituminous elements. In this case, the sensor is placed on the bottom layer before it is subjected to a temperature of $135^{\circ} \mathrm{C}$ for $24 \mathrm{~h}$ to degrade the binder resilience in order to simulate the characteristics of an old pavement. Then, the top layer is cast at $155^{\circ} \mathrm{C}$ and compacted using a heavy vibrating wheel roller. The ability of the sensor plate to survive such severe treatment is an important advantage for its use in construction.

In this work, only plates with a single inclined fibre are made and tested. These plates can only cover a small region of the member. Figure 23 shows two sensor plates that can be used together to cover a wide region in practical situations. On each plate, the fibre extends in different directions in different regions, and there are parts with no fibres (and hence no sensing capability). The use of two plates in parallel makes it possible to have the nonsensing part of one plate covered by the sensing part of the other plate. In this way, crack sensing can be performed over the whole region spanned by the two parallel plates.

Actually, the external sensor has also been applied in the field for monitoring multiple cracks. Details of the site installation and measurement will be presented in a separate publication, but the major findings are summarised below. The specific application is to monitor the formation and opening of cracks during the loading test on an old bridge in Sweden before its demolition. A crack sensor with inclined fibres running in a zigzag configuration was bonded to the bottom of the bridge. In the loading test, a total of 6 cracks with an average spacing of $7.9 \mathrm{~cm}$ were induced along the sensor. The crack opening width, measured directly on the bridge surface using a conventional fissurometer, were $0.55,0.40,0.20,0.20,0.25$ and $0.15 \mathrm{~mm}$, giving an average value 


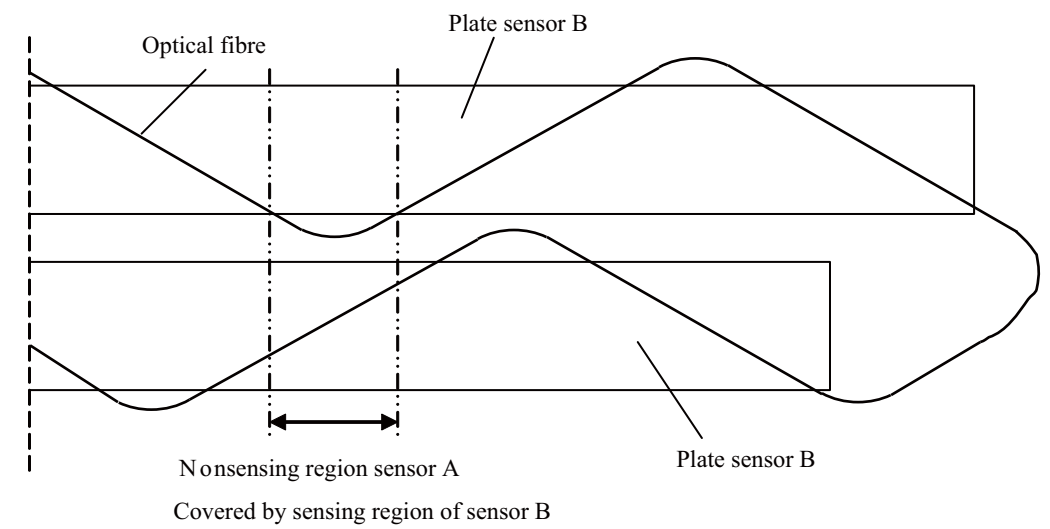

Fig. 23. Plausible arrangement for crack monitoring in practice.

of $0.29 \mathrm{~mm}$. Using our OTDR system, which has limited spatial resolution, the losses at the 6 crack locations were considered as a single power loss in the measurement. Assuming that the cracks open by the same amount, the opening of each crack was found to be between 0.283 and $0.395 \mathrm{~mm}$ according to the signal loss versus crack opening width curves obtained in the laboratory. This is in reasonable agreement with the direct measurements. Owing to the variation among the calibration curves obtained from different sensor specimens, the crack opening width was obtained within a range rather than as a single value. In practice, there is no exact quantitative relationship between crack opening width and structural durability. A reasonable estimate of the crack opening width should be sufficient for the engineer to decide whether maintenance or more detailed inspection is required.

\section{Conclusions}

In this work, an experimental study is conducted to assess the applicability of a plate sensor for crack monitoring in a wide range of materials (concrete, masonry and asphalt). Both internally embedded and surface-attached plate sensors were tested. In most cases, the measured relation between the optical loss of the sensor and the crack opening width is in good agreement with the calibration curve obtained in the laboratory.

In particular, an experiment using a bituminous element (which was prepared at a high temperature and by heavy rolling) highlights the robustness of the plate sensor under severe conditions. The material used for fabricating the sensor (Pol. 2al polyester with the addition of A1200 abrasive at $20 \%$ volume) is demonstrated to be sufficiently strong to survive the casting process of concrete and asphalt, but sufficiently brittle to crack together with the structural elements.

The results of this investigation demonstrate the viability of the plate sensor for detecting the formation and propagation of internal and external cracks in various 
materials, and for measuring the crack opening width. While the sensor can certainly be further improved, its potential for practical applications is clearly shown.

\section{Acknowledgments}

The present work was supported by the Research Project "Sustainable Bridges" (FP6PLT-01653), funded by the European Community's Sixth Framework Programme. The information presented in this paper reflects only the authors' views, and the European Community is not liable for any use that may be made of the information contained therein. The second author wishes to thank the Portuguese Foundation of Science and Technology for the PhD grant, which allowed the completion of this work. The third author acknowledges the support from the Hong Kong Research Grant Council (Project Number: UST6196/01E).

\section{References}

1 K. T. Wan and C. K. Y. Leung: Sens. Actuators, A 135 (2009) 370.

2 AASHTO LRFD: LRFD Bridge Design Specifications (American Association of State Highway and Transportation Officials, Washington D.C., 1998) 2nd ed.

3 ACI Committee 318: Building Code Requirements for Structural Concrete (ACI 318-02) and Commentary (ACI 318R-02) (American Concrete Institute, Farmington Hills, 2002).

4 CEB-FIP Provisions: European Model Code for Concrete Structures, European Committee for Concrete-International Federation of Prestressed Concrete (T. Telford, London, 1990).

5 CEN 1992. Eurocode 2: Design of Concrete Structures, CEN - European Committee for Standardization, ENV 1992-1-1.

6 E. G. Nawy: ACI J. Proc. 65 (1968) 825.

7 G. T. Halvorsen: ACI Concrete and Concrete Construction, Special Publication SP-140, 1987, p. 275.

8 RILEM TC 157 PRC: Prevention of Reflective Cracking in Pavements: State-of-the-Art Report (E \& FN Spon, London, 1997) p. 82.

9 C. K. Y. Leung, N. Elvin, N. Olson, T. F. Morse and Y. F. He: Eng. Fract. Mech. 65 (2000) 133.

10 P. J. S. Cruz, A. D. Leon, J. P. Nunes and C. K. Y. Leung: Sens. Mater. 18 (2006) 283.

11 A. W. Brown, J. P. Smith, X. Bao, M. D. DeMerchant and T. Bremner: J. Intel. Mat. Syst. Struct. 10 (1999) 340.

12 A. Oka, H. Ohno, T. Kurashima, M. Matsumoto, H. Kumagai, A. Mita and K. Sekijima: 2nd Int. Workshop on Structural Health Monitoring, Stanford, 1999, p. 672.

13 A. D. Leon: An Optical Fiber Sensor for the Crack Monitoring of Reinforced Concrete Structures, PhD Thesis, Civil Engineering Department, University of Minho, Portugal, 2007.

14 E. Bonaldo, J. A. O. Barros and P. J. B. Lourenço: Int. J. Adhesion Adhesives 25 (2005) 463.

15 J. A. O. Barros, J. T. Oliveira, P. J. B. Lourenço and E. Bonaldo: ACI Struct. J. 13 (2006) 418.

16 The Asphalt Handbook, Manual Series No. 4 (MS-4), (Asphalt Institute, Kentucky, 1989).

17 D. Gardete, L. G. Picado-Santos, and J. C. Pais: 4th Int. Symp. Maintenance and Rehabilitation of Pavements and Technological Control, Belfast, 2005.

18 H. J. Von Quintus, J. A. Scherocman, C. S. Hughes and T. W. Kennedy: Asphalt-Aggregate Mixture Analysis System, NCHRP Report 338, Transportation Research Board (National Research Council, Washington D.C., 1991). 